\title{
Applying MKE 21 FM(HD +ST) model to evaluate the ability to regenerate sand and gravel for efficient management of river exploitation and protection, (A case study at Red River crossing Phuc Tho District, Hanoi)
}

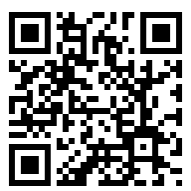

\author{
${ }^{1}$ Hanoi University of Natural Resources and Environment, Vietnam \\ 2 University of Rostock, German \\ 3 Enviromental Water Resources Institude, Vietnam \\ ${ }^{4}$ National Center for Water resources Planing and Investigation, Vietnam
}

Anh Thuc Thi Nguyen $1,{ }^{*}$, Huan Ngoc Tran 1,2 , Huong Thi Vu ${ }^{3}$, Trinh Manh Nguyen 4

\section{ARTICLE INFO}

Article history:

Received 02nd June 2020

Revised 23rdJuly. 2020

Accepted 31 st Aug. 2020

Keywords:

Eploration,

Eploitation,

Model MKE21 FM(HD +ST),

Regeneration Sand,

River bed.

\section{ABSTRACT}

Sand and gravel in River bed are common construction materials indispensable in urban development, infrastructure, and wharves ... due to the shortage of supply, throughout the rivers in Vietnam. Determination of the volume of regenerated sand annually or according to a certain cycle can use the MKE 21 FM (HF + ST) hydraulic model given by Danish Institute of Water and Environmental Engineering. Calculation results of the experimental model for the river section across the Phuc Tho district, Hanoi city show that the Vinh Khang sand mine was more simulated during period from 2010 to 2019 and still lower regenaration in the comming years. These results will be significal basis for Mining lisener to orient mine development, adjust capacity and limit exploitation in sediment-deficient areas, avoid locations where there are high erosion trend. The simulation results from the model also are scientific basis for the state management to make master plane, locate sand and gravel material potential areas. But in completing a model it takes time, synthesized data of fields such as geology, hydrometeorology, surveying, geophysics,... it is essential that the functional ministries would make coordinate to bring benefits for organizations and individuals to use lifting data to get high reliability for model results.

Copyright (C) 2020 Hanoi University of Mining and Geology. All rights reserved.

${ }^{*}$ Corresponding author

E- mail: nttanh@hunre.edu.vn

DOI: 10.46326/JMES.2020.61(4).09 


\title{
Ứng dụng mô hình MIKE 21 FM (HD+ST) đánh giá khả năng tái tạo cát, sỏi, phục vụ quản lý hiệu quả hoạt động khai thác, bảo vệ dòng sông. (Thử nghiệm tại đoạn sông Hồng qua Huyện Phúc Thọ, Hà Nội)
}

\author{
Nguyễn Thị Thục Anh 1, , Trần Ngọc Huân 1,2 Vũ Thị Hương ${ }^{3}$, Nguyễn Mạnh Trình ${ }^{4}$ \\ 1 Trưòng Đại học Tài nguyên và Môi truờng Hà Nội, Việt Nam \\ 2 Đại học Rostock, Công hòa Liên bang Đức \\ 3 Viện Tài nguyên Môi trường nước, Việt Nam \\ 4 Trung tâm Quy hoạch và Điều tra Tài nguyên nước, Bộ Tài nguyên và Môi trưòng, Việt Nam
}

THÔNGTINBÀI BÁO TÓMTẮT

Quá trình:

Nhận bài 02/ 06/ 2020

Sửa xong $23 / 07 / 2020$

Chấp nhận đăng31/ 08/ 2020

\section{Tù khóa:}

Thăm dò,

Khai thác,

Mô hình MIKE21 FM

(HD+ST),

Tái tạo cát sỏi lòng sông.
Cát, sỏi lòng sông là vật liệu xây dựng thông thường không thể thiếu trong phát triển đô thị, cơ sở hạ tầng, cầu cảng,... Xác định khối lương cát tái tạo hàng năm hoăc theo chu kỳ nhất định có thể sử dụng mô hình toán thủy lực MIKE $21 \mathrm{FM}(\mathrm{HF}+\mathrm{ST})$ của Viên kỹ thuật Tài nguyên nước và Môi trường Đan Mach. Kết quả tính toán mô hình áp dụng thử nghiệm cho đoạn sông qua địa phận huyện Phúc Tho, thành phố Hà Nội cho thấy, quá trình thành tạo mỏ cát Vĩnh Khang đước mô phỏng trong thời gian tù 2010 đến 2019 có sự tái tạo cát mở rộng bãi bồi và vẫn có xu thế tái tạo với tốc độ và quy mô nhỏ hơn trong nhũng năm tiếp theo. Kết quả có được là cơ sở khoa học giúp các nhà quản lý định hướng quy hoạch vung nguyển liệu cát, sỏi. Tuy nhiên, phưong pháp mô hình toán thủy lực yêu cầu đầu tư lớn về thời gian, mức độ chi tiết của thông tin đầu vào cho địa hình đáy sông, tài liệu địa chất, khítượng thủy văn, trắc địa,... do vậy, rất cần có sự phối hợp của các bộ, ngành chức năng để khai thác sử dụng các nguồn dữ liệu sẵn có để có thể nâng cao mức độ tin cộy kết quả của mô hình.

C 2020 Trường Đại học Mỏ - Địa chất. Tất cả các quyền được bảo đảm.

\section{Mở đầu}

Hoạt động khai thác cát sỏi lòng sông chịu sự ảnh hưởng rất nhiều từ chính đặc điểm tự nhiên của dòng sông. Lũ lụt, thiếu hụt trầm tích, tác động

${ }^{*}$ Corresponding author

E - mail: nttanh@hunre.edu.vn

DOI: 10.46326/ JMES.2020.61(4).09 của con người, nhu cầu vật liệu,... Không chỉ Việt Nam, các quốc gia khác cũng luôn phải có ứng xử thích hợp (Dulmini, 2009). Đối với hệ thống sông Mê Kông, các nghiên cứu cho thấy đã có sự xói lở được xem như là tai biến do tác động đồng thời của tự nhiên và con người, hoạt động trị thủy do các đáp chắn trên dòng đã có tác động bất lợi cho tính chất cơ lý đường bờ cũng như hạn chế sự lắng đọng phù sa, giảm thiểu tài nguyên cát sỏi lòng sông (Dinh Cong San, 2005; Walling, 2010). Hiện 
trạng này cũng tương đồng như đối với các hệ thống sông khác ở Việt Nam và rất cần có chương trình đánh giá tổng thể sự thay đổi lượng cát tái tạo. Lựa chọn các mô hình khác nhau trong tính toán thủy lực áp dụng cho các dòng sông sẽ góp phần bổ sung thông tin phục vụ quy hoạch tổng thể sử dụng dòng sông.

Mô hình MIKE21 FM(HD+ST) do Viện kỹ thuật Tài nguyên nước và Môi trường Đan Mạch thiết lập đã được ứng dụng khá nhiều để nghiên cứu động lực và diễn biến xói bồi lòng sông, trong đó mô hình MIKE 11 thường sử dụng để tính toán sơ bộ và lấy kết quả làm điều kiện biên cho mô hình MIKE 21 FM (HD+ST). Đã có nhiều quốc gia sử dụng mô hình này để lập cơ sở khoa học cho quy hoạch phát triển công trình công cộng bên bờ sông, hoạt động công nghiệp, du lịch, giao thông vận tải như: dự án xây dựng cầu qua sông Bramaputra - Jamura ở Bangladesh (Sarker và nnk, 2014); dự án ổn định nút thắt nhập lưu Chatomuk giữa các sông Bassac, Mekong, Tonlesap của Campuchia (Walling, 2010); một số đoạn sông Cửu Long đã được Viện Khoa học Thủy lợi miền Nam ứng dụng mô hình MIKE 11 và MIKE 21C trong các đề tài nghiên cứu, từ những năm 2000 đến 2010 ở Long Xuyên trên sông Hậu, Tân Châu trên sông Tiền, Thanh Đa trên sông Sài Gòn (Dinh Cong San, 2005); một số đoạn sông Hồng được Viện Khoa học Thủy lợi, Đại học Thủy lợi ứng dụng mô hình MIKE 11 và MIKE 21 FM tại đoạn Sơn Tây - Liên Trì, đoạn sông Thái Bình, khu vực Hải Dương (Phạm Đình, Nguyễn Ngọc Đằng, 2010; Lương Phương Hậu, 2010),... Nhìn chung kết quả mô phỏng của mô hình MIKE 21 FM (HF+ST) trong các dự án này được đánh giá là khá phù hợp thực tế. Mô hình MIKE $21 \mathrm{FM}(\mathrm{HF}+\mathrm{ST})$ có ưu điểm là tạo lưới tính "mềm dẻo".

\section{Dữ liệu và phương pháp nghiên cứu}

\subsection{Khu vực nghiên cúu}

Khu vực thử nghiệm tại loạt bãi bồi Vĩnh Khang có diện tích khoảng $2 \mathrm{~km} 2$ và tại khu vực đang có hoạt động khai thác khoáng sản cát, sỏi lòng sông thuộc huyện Phúc Thọ, Thành phố Hà Nội. Vị trí khu vực thử nghiệm được thể hiện trên Hình 1, 2.

Quan sát trên ảnh vệ tinh có thể thấy trong diện tích bãi bồi đã mất đi tài nguyên cát, sỏi khá lớn do hoạt động khai thác cát. Hai lớp trầm tích chính đặc trưng cho địa chất vùng đồng bằng sông Hồng là trầm tích Pleistocen và trầm tích Holocen (Lại Mạnh Giàu,2017) gồm chủ yếu là các trầm tích sét, bột, cát chứa nhiều vật liệu vụn thể hiện sự tích tụ đặc trưng cho hoạt động của lưu vực sông (Liên đoàn Integeo, 2020).

\subsection{Dũ liệu nghiên cúru}

Dữ liệu để thiết lập mô hình là tài liệu địa hình đáy sông khu vực mỏ thăm dò và vùng lân cận gồm các tuyến đo mặt cắt ngang được đo vẽ hàng năm trên hạ du sông Hông theo Cục quản lý đê điều và phòng chống lụt bão (2014) và Tổng cục Khí tượng - Thủy văn (2016). Ngoài ra, dữ liệu được cung cấp, cập nhật, đo đạc trong quá trình thực hiện đề tài khoa học công nghệ cấp Bộ MS. 2017.03.12 với các đợt khảo sát, thăm dò, đo đạc bổ sung địa hình đáy sông khu vực thăm dò vào năm 2018, 2019 và 2020 (Liên đoàn Integeo, 2020), bản đồ địa hình $1 / 5.000$ thực hiện đo vào tháng 4/ 2010 do Viện khoa học Thủy lợi Việt Nam thực hiện và một số nghiên cứu trước đây về biến đổi lòng dẫn sông Hồng và khu vực mỏ Vĩnh Khang (Phạm Đình, 2010).

\subsection{Phương pháp nghiên cứu}

Các phương pháp nghiên cứu đã thực hiện bao gồm các phương pháp truyền thống của tổ hợp thăm dò khoáng sản: nghiên cứu ảnh viễn thám, khảo sát thực địa, sử dụng các công trình khai đào: dọn vết lộ, đào hố, khoan, lấy các loại mẫu phân tích theo đúng quy phạm thăm dò. Đồng thời, tiến hành đo vẽ địa hình đáy sông trên các tuyến chuẩn và đặc biệt là ứng dụng mô hình MIKE 21 FM (HF+ST). Số liệu bùn cát được tiến hành thu thập qua công tác lấy mẫu trong 12 đợt khảo sát năm 2018, tại các thủy trực trên các mặt cắt, tiến hành lấy mẫu phù sa lơ lửng theo phương pháp tích điểm, mỗi thủy trực lấy tại 3 điểm mặt $(0,2 \mathrm{~h})$, giữa $(0,6 \mathrm{~h})$ và đáy $(0,8 \mathrm{~h})$ sử dụng dụng cụ lấy mẫu kiểu chai. Các mẫu phù sa lơ lửng được lọc bằng giấy lọc tại chỗ và sau đó tiến hành cân sấy trong phòng thí nghiệm.

Từ các kết quả phân tích mẫu, tiến hành tính toán độ đục tại từng vị trí, lưu lượng bùn cát và cuối cùng tính toán lưu lượng bùn cát lơ lửng chuyển qua một mặt cắt ngang. Bên cạnh đó, mẫu đất trên bề mặt lưu vực và mẫu phù sa đáy cũng 


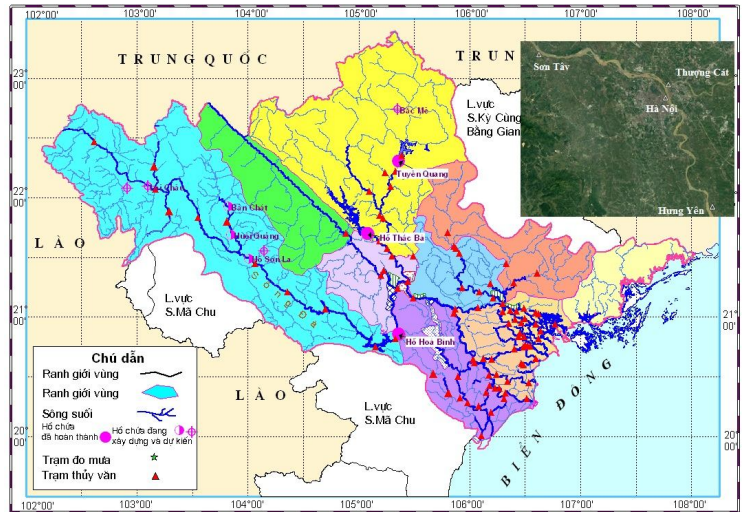

Hình 1. Hệ thống sông Hồng và vị trí thử nghiệm tại khu vực Bãi Vĩnh Khang.

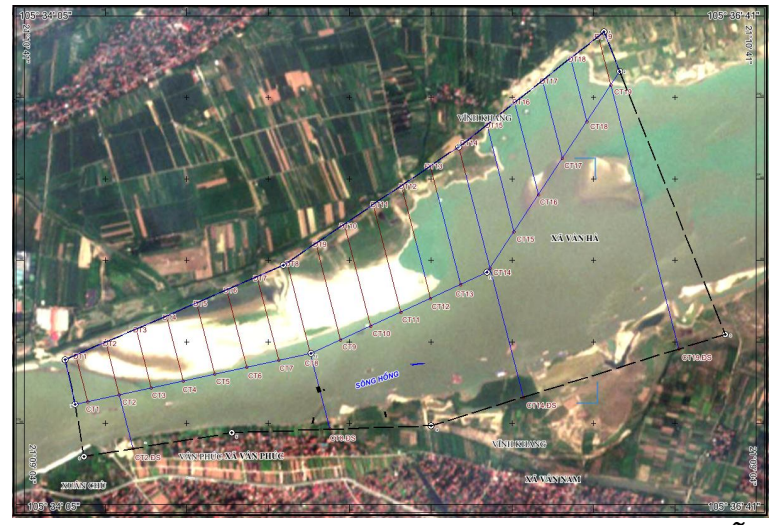

Hình 2. Vị trí khu vực thử nghiệm qua ảnh viễn thám, thu nhận 2020 (Đề tài MS.2017.03.12).

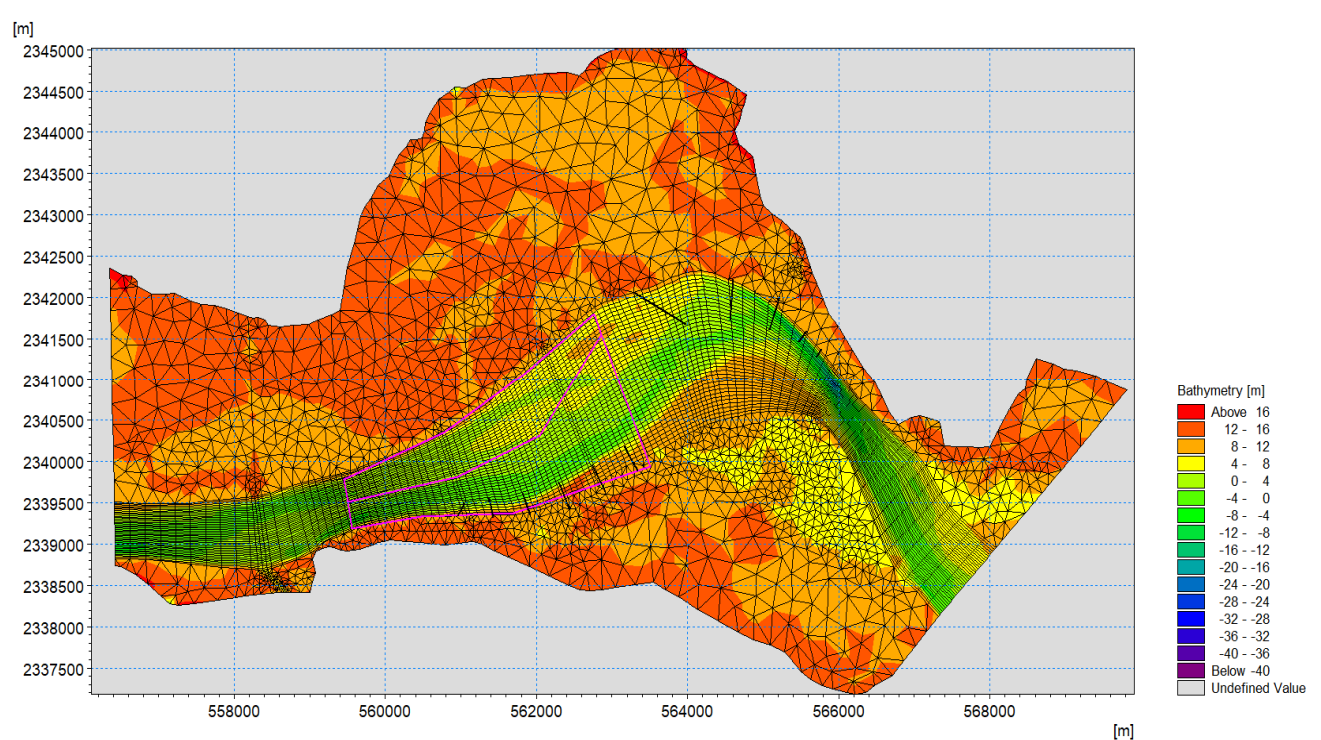

Hình 4. Mô phỏng địa hình khu vực mô phỏng bằng mô hình MIKE 21.

được thu thập và sử dụng để phân tích cấp hạt phục vụ tính toán bằng mô hình.

Các bước thiết lập Mô hình đã thực hiện rất tuần tự và sử dụng tối đa các dữ liệu có giá trị đã có.

\subsubsection{Thiết lập lưới tính toán}

Đối với mô hình MIKE 21 FMthì việc tạo ra một lưới thích hợp là cần thiết để nhận được các kết quả tin cậy từ mô hình. Dựa trên các tài liệu địa hình, địa chất, tài liệu về lưu lượng, mực nước, nồng độ bùn cát của đoạn sông để xây dựng mô hình xác định các thông số mô phỏng cơ bản:

+Bản đồ địa hình 1/ 5.000 đo tháng 4/2010;

+Tài liệu thủy văn gồm: mực nước lưu lượng, nồng độ bùn cát tại các biên;

+ Tài liệu liên quan đến đặc tính bùn cát lơ lửng, bùn cát đáy khu vực mỏ như kích thước hạt, tỷ lệ bùn cát, độ rỗng, trọng lượng riêng;
+Tài liệu về công trình chỉnh trị dòng chảy khu vực;

+ Tài liệu mặt cắt địa chất khu vực mỏ (Đoàn Địa chất 301, 2009; Sở Tài nguyên và Môi trường Hà Nội, 2013; Sở Khoa học và Công nghệ Hà Nội, 2015).

Tiến hành thiếp lập lưới mô hình số 2D khu vực mỏ Vĩnh Khang trong MIKE Zero được lưu dưới dạng file Mesh Generator (.mdf).

Các bước xây dựng lưới tính toán như sau:

- Chọn hệ quy chiếu UTM, múi 48;

- Xác định giới hạn vùng tính toán:

+Biên cứng xác định phạm vi phần bãi sông và phần lòng sông;

+Biên vào, biên ra của mô hình.

- Tao lưới theo các kích thước lưới khác nhau: lưới tính toán trong lòng sông được chia dày hơn 
so với phần bãi sông. Kích thước ô lưới L x B =75 x 45 m (Hình 4).

\subsubsection{Thiết lập các điều kiện biên}

Biên của mô hình bao gồm điều kiện biên trên và biên dưới. Biên trên chọn là quá trình lưu lượng và nồng độ bùn cát, biên dưới là quá trình mực nước tương ứng cùng thời kỳ. Chi tiết các biên như sau:

+ Số liệu thủy văn, nồng độ bùn cát tại biên thượng lưu (tại Cẩm Đình) được trích xuất từ mô hình tổng thề;

+Mực nước tại biên dưới (tại Liên Hông) được trích xuất từ mô hình tổng thể.

Thiết lập được chuỗi số liệu biên trên, biên dưới về lưu lượng, mực nước, nồng độ bùn cát trong điều kiện hiện trạng và kịch bản tính toán MIKE 21 FM(HD+ST).

- Lưu lượng dòng chảy và độ đục tương ứng (biên trên) năm 2010.

- Mực nước tại hạ lưu Liên Hồng (biên dưới) năm 2010.

- Đường kính hạt bùn cát đáy D50 =0,02 m.

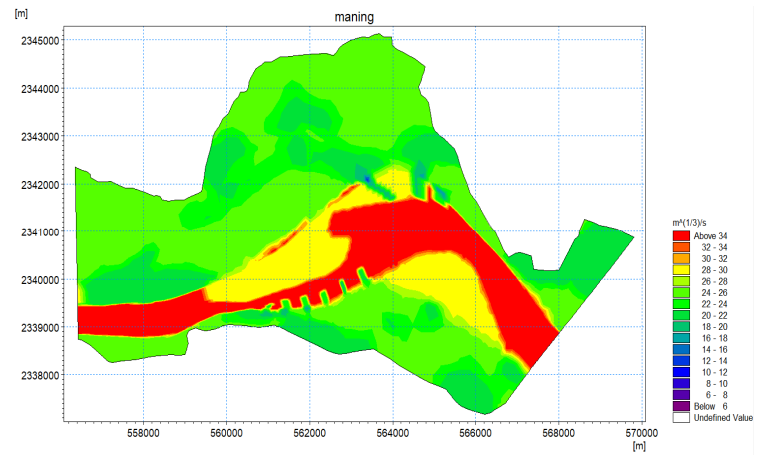

Hình 5. Phân bố hệ số nhám địa hình.

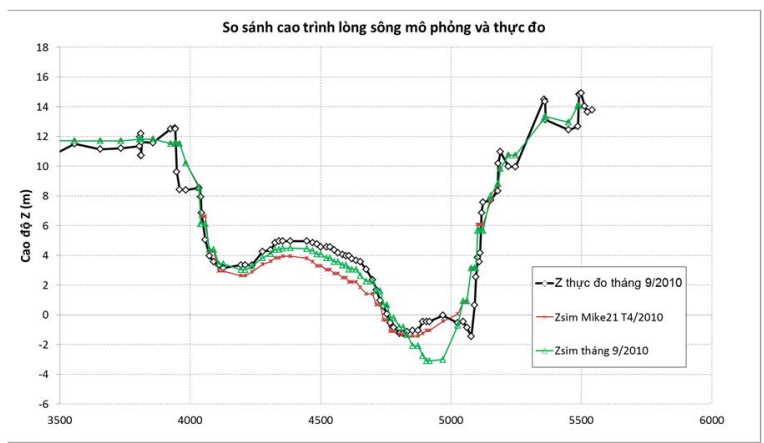

Hình 7. So sánh cao trình đáy sông tại mặt cắt 55 giũa tính toán (màu xanh) và thực đo (màu đen).
Hệ số nhám đia hình lòng dẫn $0,03 \div 0,035$ (Phạm Đình, 2010; Lương Phương Hậu, 2010; Viện Quy hoạch Thủy Lợi, 2005), (Hình 5).

\subsubsection{Thiết lập điều kiện ban đầu}

Điều kiện ban đầu là các giá trị lưu lượng và mực nước, độ đục tại thời đoạn đầu tại các vị trí trển miền tính toán. Dựa vào chuỗi số liệu khống chế thượng và hạ lưu mỏ cát Vĩnh Khang được trích xuất từ mô hình tổng thể và tiến hành xác định giá trị phù hợp ứng với các trường hợp mô phỏng.

\subsubsection{Kiểm định sự ổn định của mô hình}

Việc xây dựng mô hình thủy động lực cho đoạn sông Hồng từ Sơn Tây về Hưng Yên là để đánh giá khái quát quá trình vận chuyển bùn cát trên toàn tuyến, đồng thời xác định một số thông số, điều kiện biên cho khu vực mỏ Vĩnh Khang. Tuy nhiên, trong quá trình xây dựng mô hình chi tiết trong phạm vi khu vực mỏ, nghiên cứu chỉ có thể tiến hành mô phỏng, thử nghiệm quá trình vận chuyển bùn cát vào cho 1 thời điểm bất kỳ (tháng 9/2010) để xác định tính hợp lý của mô hình. Để xác định

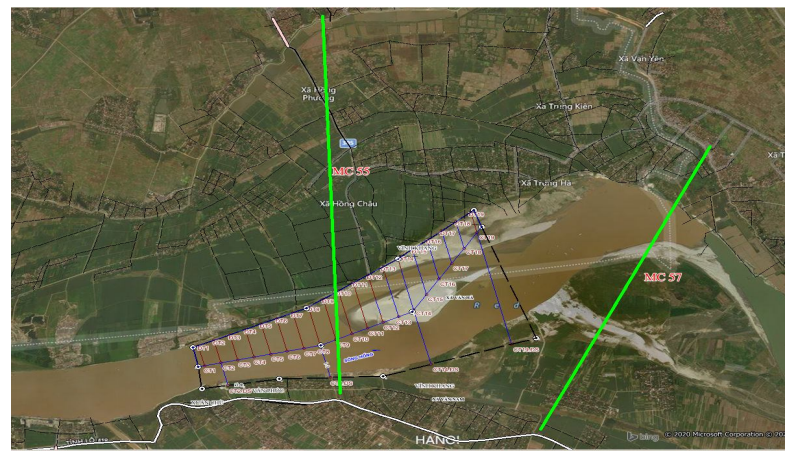

Hình 6. Bản đồ vị trí mặt cắt kiểm tra hình thái (Cục Đê Điều, 2014; Tổng cục khí tượng - thủy văn, 2016).

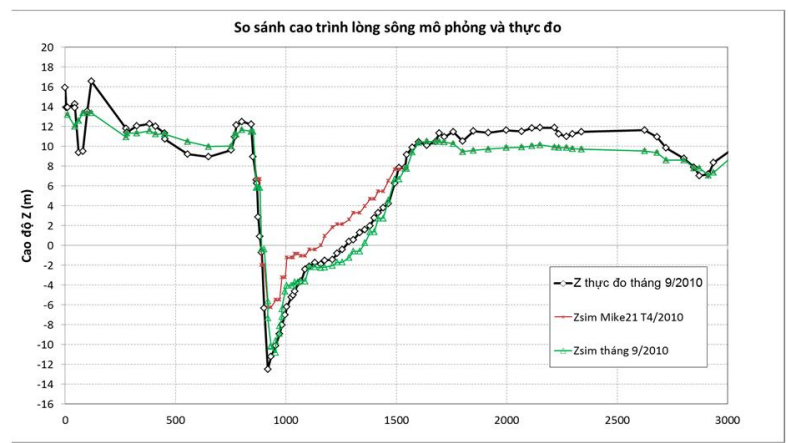

Hình 8. So sánh cao trình đáy sông tại mặt cắt 57 giũa tính toán (màu xanh) và thực đo (màu đen). 
các thông số mô phỏng phù hợp, mô hình được hiệu chỉnh bằng so sánh hình thái mặt cắt ngang. Sử dụng địa hình tháng 4/ 2010 mô phỏng để kiểm định hình thái mặt cắt vào tháng $9 / 2010$ tại mặt cắt (MC) số 55, 57 (Hình 6, 7, 8).

\section{Kết quả nghiên cứu và thảo luận}

So sánh kết quả tính toán từ mô hình $2 \mathrm{D}$ với bản đồ vệ tinh sau mùa lũ năm 2010 cho thấy có sự tương đồng về vị trí khu vực bồi lắng. Biến đổi trên mặt cắt ngang địa hình tại $\mathrm{MC}$ số 55 và 57 có xu thế tương đối phù hợp với mặt cắt ngang địa hình thực đo. Sai số diện tích ướt: MC 55 (1,2\%),

Theo diễn biến tái tạo cát của mô hình, khu vực mỏ nên thiết kế theo hướng tiến từ hạ lưu về thượng lưu và khai thác theo phương thức dải khấu, tránh tập trung vào diện hẹp và nên di chuyển tàu hút hoặc xà lan men theo dải cát. Về công tác cấp phép, chỉ nên cấp cho một chủ đầu tư có năng lực, thay vì chia quá nhỏ thành nhiều giấy phép. Như vậy, công tác quản lý hoạt động khai thác cũng như cấp quyền khai thác được thuận lợi hơn. Công suất khai thác chỉ nên tính toán cân

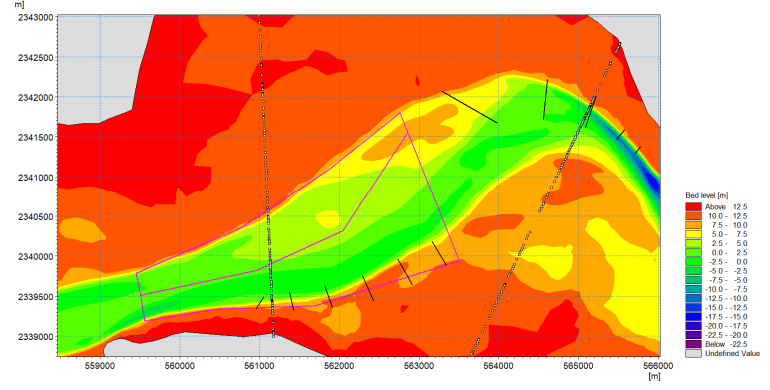

Hình 9. Địa hình bắt đầu mô phỏng.

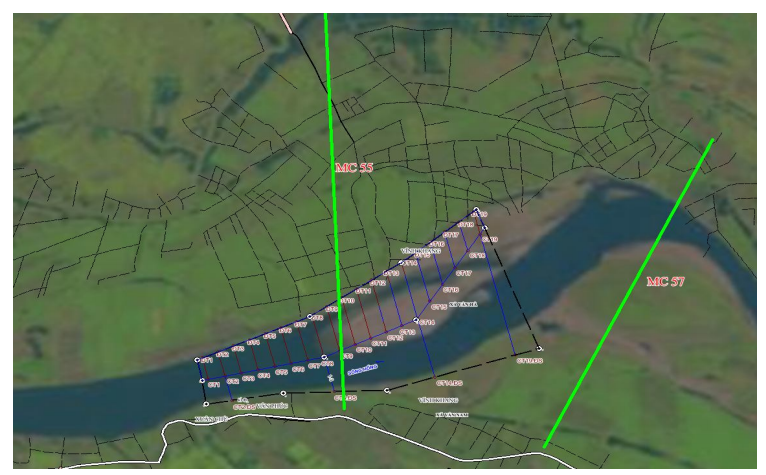

Hình 11. Ảnh vệ tinh khu vục bãi Vĩnh Khang tháng 10/ 2010.
MC 57 (1,1\%), chênh lệch độ cao bãi bồi lớn nhất tại MC55 là 0,46 m (Hình 9, 10,11).

Sáu kịch bản từ bãi tự nhiên chưa khai thác, chia thành các khu vực phát triển theo trình tự khai thác tránh tổn thương dòng sông được mồ phỏng trên Hình 13.

Kết quả mô phỏng các kịch bản cho thấy:

+ Trong điều kiện tự nhiên mùa lũ có tốc độ tái tạo (bồi lấp) lớn nhất đạt từ $0,01 \div 0,09 \mathrm{~m} /$ ngày, mùa khô tốc độ tái tạo giảm xuống, mức tái tạo $<0,02 \mathrm{~m} /$ ngày.

+Sau khai thác, tốc độ tái tạo (bồi lấp) mùa lũ giảm xuống đạt từ $0,01 \div 0,07 \mathrm{~m} /$ ngày, mùa khô có xu thế tăng lên nhưng không lớn.

bằng với lượng cát tái tạo hàng năm. Riêng phần bãi bồi bán ngập nước chỉ khai thác phần bồi lắng nhô lên sau mùa lũ và kết thúc đáy moong ở độ cao bằng mức nền trước khi khai thác.

\section{Kết luận và kiến nghị}

Kết luận:

- Kết quả tính toán của mô hình đối với khu vực thử nghiệm đã cho thấy trong những năm từ 2010 đến 2019 đã có sự bồi lắng trầm tích, mở rộng

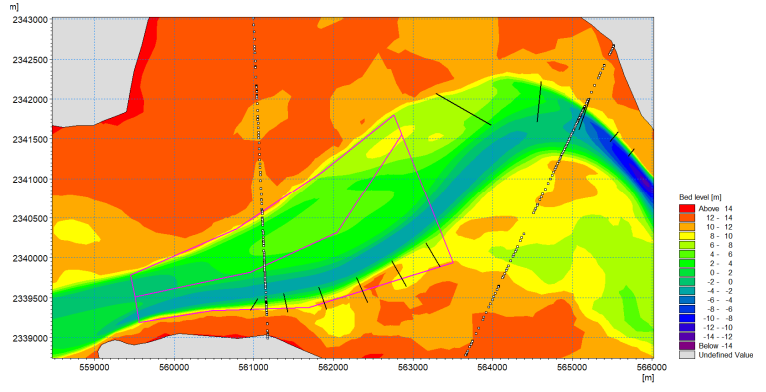

Hình 10. Kêt quả mô phỏng sự biến đổi địa hình đến tháng 10/ 2010 bằng MIKE 21ST.

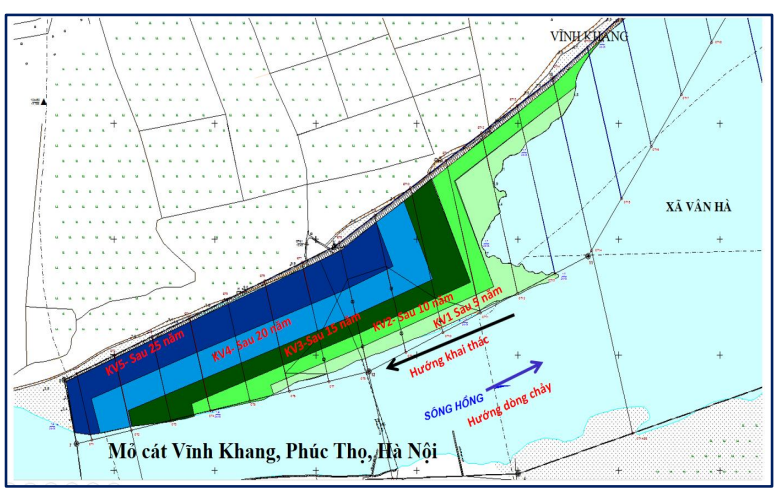

Hình 12. Sơ đồ các giai đoạn và vị trí khai thác cát mỏ cát Vĩnh Khang, huyện Phúc Thọ, Hà Nội. 
không gian bãi bồi, tập trung vào bờ trái dòng sông. Xu thế bồi vẫn tiếp tục những năm tiếp theo, tuy nhiên tốc độ bồi lắng không cao. Lựa chọn mô hình MIKE 21 FM (HD+ST) cho thấy, có sự phù hợp và có cơ sở khoa học, thực tiễn cao trong quản lý hiệu quả hoạt động khai thác bảo vệ dòng sông.

- Mô hình MIKE 21 FM (HD+ST) có thể ứng dụng tính toán dự báo khu vực có khả năng tái tạo
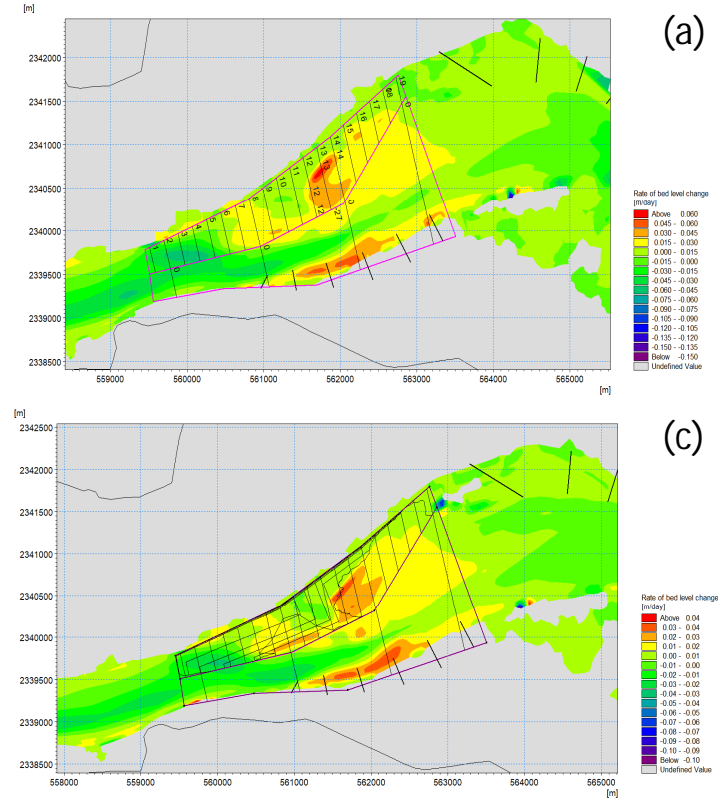

(c)
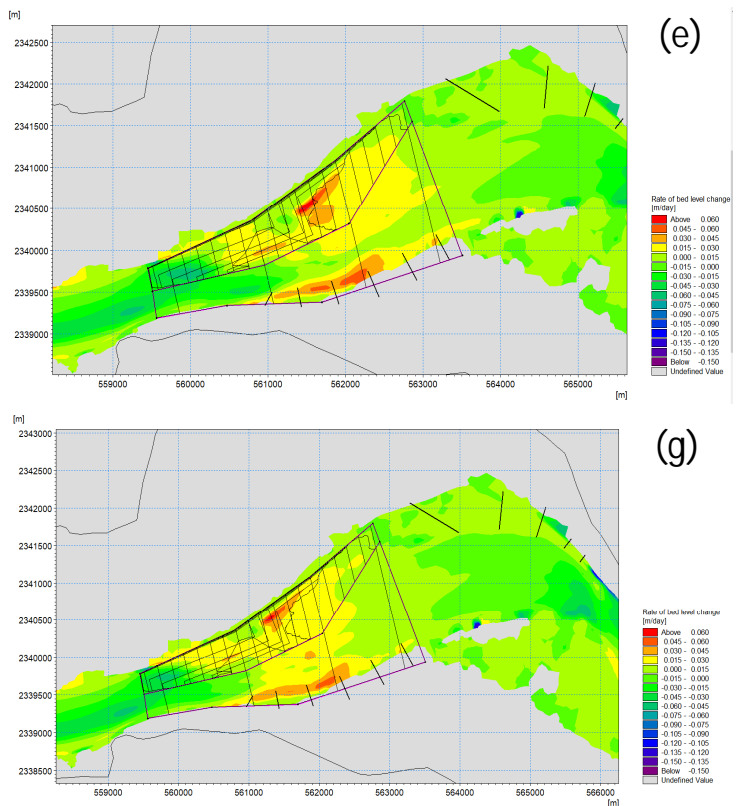

(g)

Hình 13. Biểu đồ tốc độ tái tạo bùn cát tại mỏ Vĩnh Khang theo các kịch bản (a *k)

a) - Tốc độ tái tạo bùn cát (m/ngày) - Hiện trạng; b) - Tốc độ tái tạo theo thời gian trong năm dọc bãi, mùa lũ (đưòng bao mầu đỏ); c) - Sau 3 tháng kiệt - Sau 5 năm khai thác; d) - Sau 5 năm khai thác; e) - Sau 3 tháng kiệt - Sau 10 năm khai thác; f) - Sau 10 năm khai thác; g) - Sau 3 tháng kiệt - Sau 15 năm khai thác; h) Sau 15 năm khai thác; cát, sỏi lòng sông tạo cơ sở khoanh định diện tích dựa vào diện quy hoạch thăm dò khoáng sản vật

- Mô hình các kịch bản khai thác cát theo các giai đoạn $5,10,15,20$ và 25 năm chỉ ra có sự tập trung bồi ở đoạn sông qua địa phận huyện Phúc Thọ. Quy mô và tốc độ bồi lắng, tái tạo cát khác nhau.
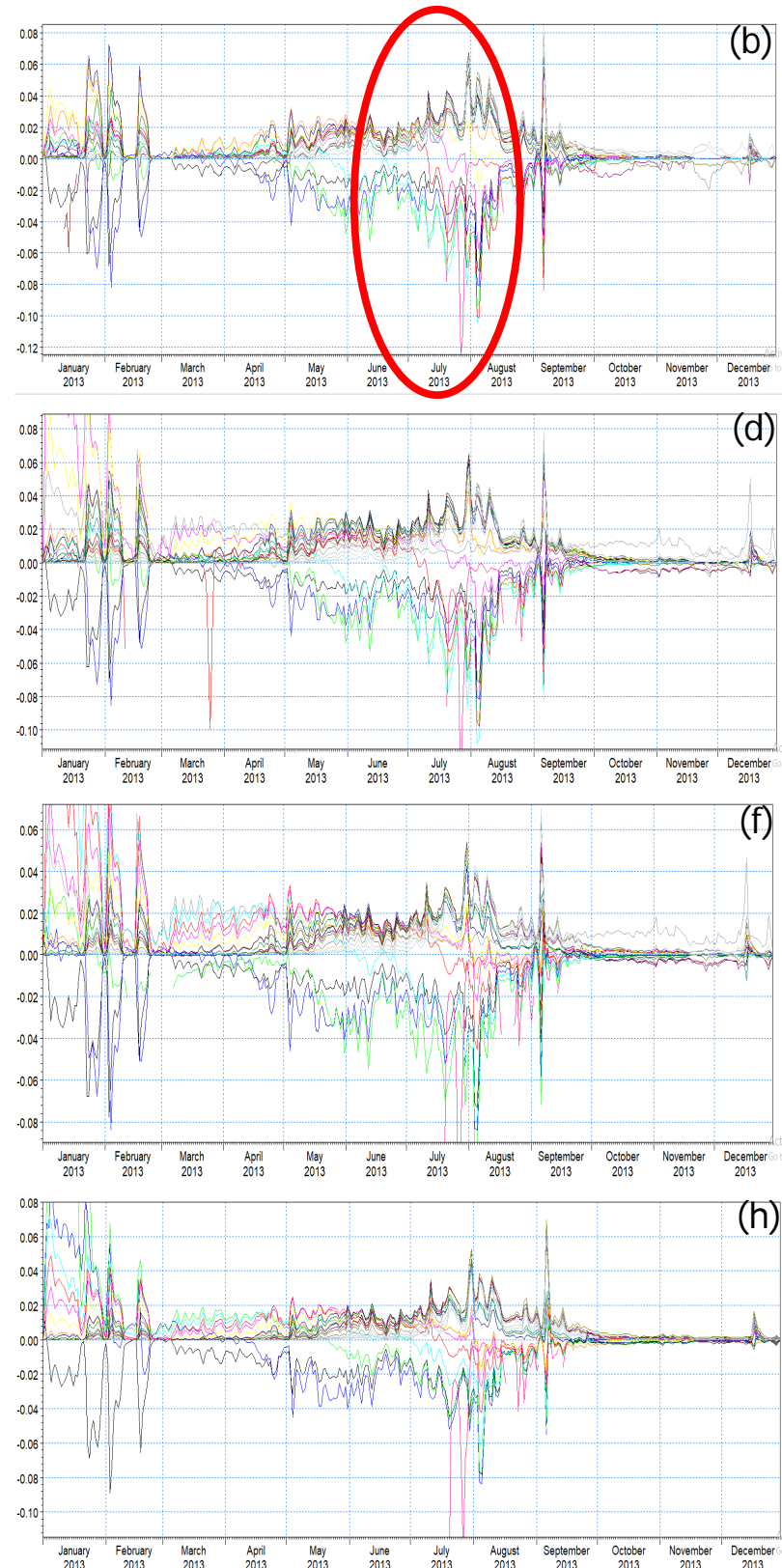

(h)

\section{(1)} liệu xây dựng thông thường. 

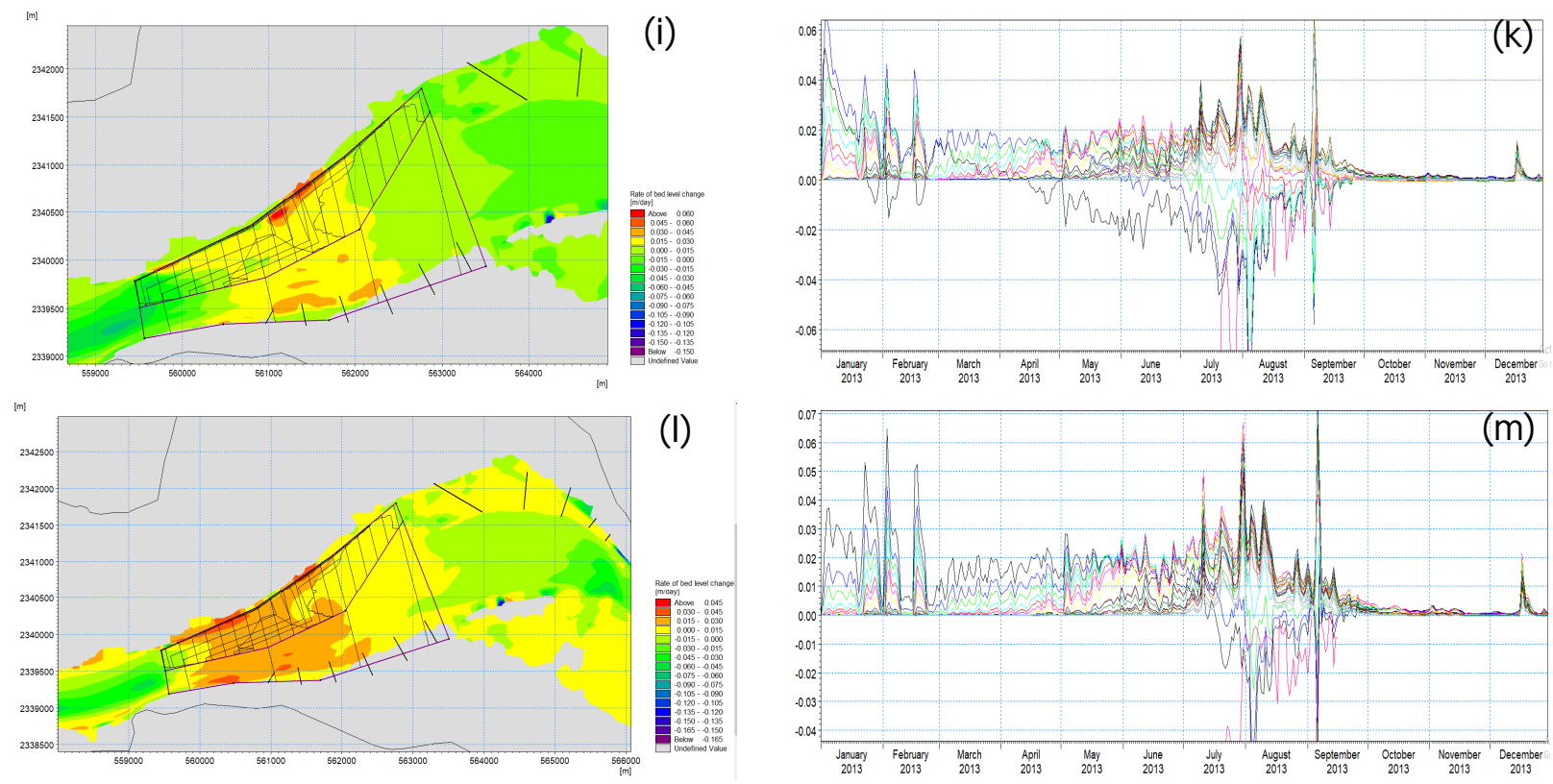

Hình 13. Biểu đồ tốc độ tái tạo bùn cát tại mỏ Vĩnh Khang theo các kịch bản $(1 \div \mathrm{m})$

i) - Sau 3 tháng kiệt - Sau 20 năm khai thác; k) - Sau 20 năm khai thác.

l) - Sau 3 tháng kiệt - Sau 25 năm khai thác; m) - Sau 25 năm khai thác.

- Tài nguyên, trữ lượng cát tính toán được qua các phương pháp thăm dò theo quy định hiện hành được huy động vào thiết kế khai thác là hợp lý, song cần xem xét đến khối lượng cát bồi lắng để có thể cân đối công suất thiết kế cho phù hợp, theo đó việc gia hạn giấy phép khai thác cũng có cơ sở khoa học khi diện tích có khả năng tái tạo cát.

- Để bảo vệ dòng sông, trữ lượng huy động vào khai thác nên tính toán nhỏ hơn lượng cát tái tạo. Việc xác định mức nền khai thác cát lòng sông phần ngập nước nên căn cứ vào hiện trạng địa hình đáy sông.

- Quá trình thiết lập mô hình có thời gian dài, ổn định về chế độ máy móc, số liệu đa dạng từ địa chất, khí tượng thủy văn, đặc điểm hình thái sông,... do vậy, cần có sự phối hợp của các đơn vị chức năng của Bộ Tài nguyên và Môi trường tạo sự thuận lợi trong triển khai khảo sát, đo vẽ cũng nhưng sử dụng thông tin.

Kiến nghị:

- Cần tiếp tục nghiên cứu, ứng dụng các mô hình toán thủy lực trong hoạt động điều tra, thăm dò , khai thác khoáng sản, coi đó là một công cụ để thử nghiệm trên một số hệ thống sông khác nhau.

- Mô hình MIKE21 FM(HD+ST) nên được xem là một công cụ mô phỏng, áp dụng hiệu quả cho dự báo tiềm năng phát triển các mỏ cát, song tính toán trũ lượng cát thì phải sử dụng hệ thống các phương pháp thăm dò theo quy định hiện hành.

- Triển khai tập huấn, hướng dẫn các tổ chức, cá nhân có sử dụng mô hình để có xây dựng bộ dữ liệu dự báo khả năng tái tạo cát hàng năm.

\section{Lời cảm ơn}

Nhóm tác giả xin gửi lời cảm ơn do nhận được tư liệu từ đề tài Mã số TNMT 2017.03.12: "Nghiền cúu co sở khoa hoc đôi mới cơ chế, phương thức thăm dò, khai thác cát, sỏi để bảo vệ dòng sông", Bộ Tài nguyên và Môi trường, Việt Nam.

\section{Tài liệu tham khảo}

Cục quản lý đê điều và phòng chống lụt bão (2014). Mặt cắt ngang sông Hồng từ 2001 đến 2014, Bộ Nông nghiệp và phát triển Nông thôn.

Đoàn Địa chất 301 (2009). Báo cáo kết quả thăm dò cát san lấp bãi nổi sông Hồng tại xã Liên Hồng, huyện Đan Phượng, thành phố Hà Nội, 80 Trang.

Des E. Walling, (2010). The sediment load of the Mekong River.The Mekong, Elsevier Inc, 113142. doi:10.1016/ b978-0-12-374026- 
Dinh Cong San, (2005). Research on river bed erosion and sedimentation prediction by MIKE 21C model at Tan Chau-Hong Ngu area, in the Mekong River. Proceedings of the International Symposium on Sustainable Development in the Mekong River basin, Vientiane, Lao PDR. 188195, 188-195.

Dulmini Jayewardana, (2009). River sand mining and management; Case study in Nilwala river basin - Sri Lanka. Annual Forestry and Environment Symposium, University of Sri Jayewardenepura, Sri Lanka.

Lại Mạnh Giàu, (2017). Nghiên cứu đặc điểm cấu trúc địa chất trũng sông Hồng theo tài liệu địa vật lý phục vư điều tra tài nguyên than. Luận án tiến sĩ địa chất, Trường Đại học Mỏ - Địa chất, 136 trang.

Liên đoàn Integeo, (2020). Báo cáo kết quả thăm dò khu vực mỏ Vĩnh Khang. Đề tài cấp Bộ Tài nguyên và Môi truòng, MS.TNMT.2017.03.12.

Lương Phương Hậu, (2010). Nghiên cứu dự báo xói lở, bồi lắng lòng dẫn và đề xuất các biện pháp phòng chống cho hệ thống sông đồng bằng Bắc Bộ-mã số KC-08-11, Bộ Khoa học và Công nghệ.

Phạm Đình, Nguyễn Ngọc Đẳng (2010). Nghiên cứu diễn biến lòng dẫn sông Hồng và đề xuất giải pháp ổn định khu vực cửa vào sông Đáy. Viện khoa học Thủy lợi Việt Nam. Tạp chí Khoa học và công nghệ Thủy lọi 05+06, 126-135. ISSN: 18594255

Sở Khoa học và Công nghệ Hà Nội, (2015). Báo cáo đặc điểm địa chất và khoáng sản thành phố Hà Nội.

Sở Tài nguyên và Môi trường thành phố Hà Nội, (2013). Báo cáo kết quả thăm dò mỏ cát làm vật liệu san lấp tại bãi nổi sông Hồng lô 1 thuộc xã Hồng Hà, huyện Đan Phượng, TP Hà Nội.

Tổng cục Khí tượng - Thủy văn, (2016), Dữ liệu mặt cắt ngang sông Hồng 2016, Bộ Tài nguyền và Môi trường.

Viện Quy hoạch Thủy Lợi, (2005). Báo cáo tổng hợp quy hoạch sử dụng tổng hợp nguồn nước lưu vực sông Hồng - Thái Bình. 